Revista ACB: Biblioteconomia em Santa Catarina, Florianópolis, v. 22, n. 2, ESPECIAL, p. 161-179, abr./ jul., 2017.

Anais do $35^{\circ}$ Painel Biblioteconomia Santa Catarina.

Chapecó

Recebido em: 09-03-2017 Aceito em: 05-05-2017

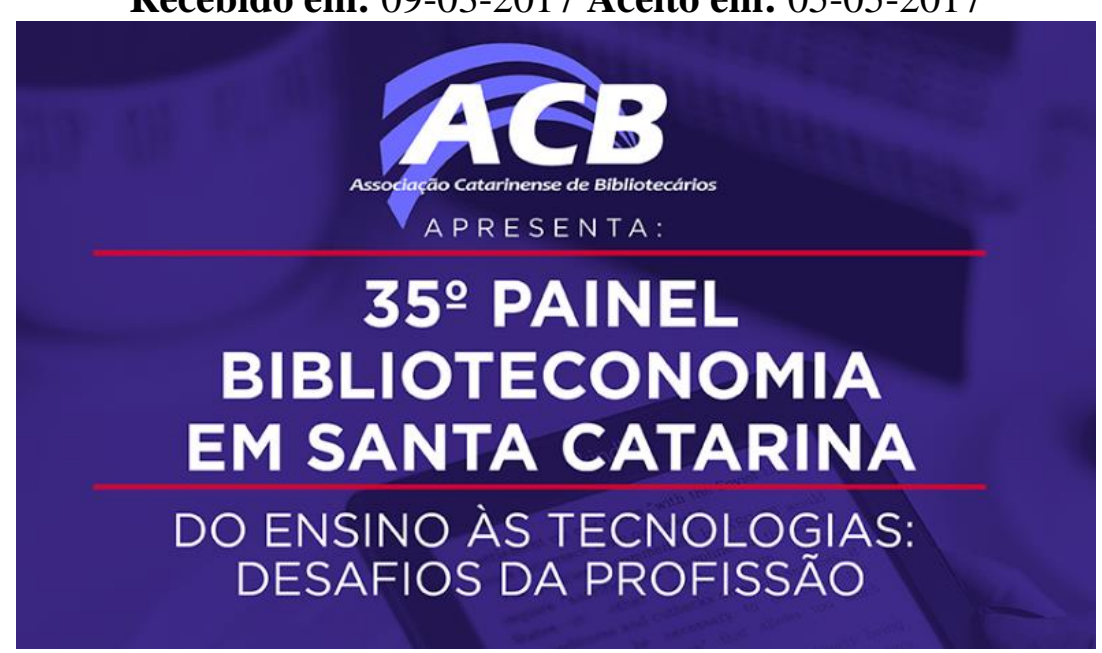

\title{
AVANÇOS, PERSPECTIVAS E LIMITAÇÕES DA LEI No 12.244/2010 COM VISTAS A SUA APLICABILIDADE: \\ ANÁLISE DA LITERATURA BRASILEIRA E AÇÕES DOS ÓRGÃOS DE CLASSE DO ESTADO DE SANTA CATARINA (BRASIL)
}

\section{Juliano Ricardo Zimmermann ${ }^{1}$ \\ Viviane Carolina de Paula ${ }^{2}$ \\ Maria Lourdes Blatt Ohira ${ }^{3}$}

\begin{abstract}
Resumo: Apresenta os resultados da análise de artigos de periódicos publicados a partir da promulgação da Lei $\mathrm{n}^{\circ}$ 12.244/2010, que dispõe sobre a universalização das bibliotecas nas instituições de ensino do país. Aborda sobre o papel, a missão e a função da Biblioteca Escolar e as atribuições do Bibliotecário na escola. O levantamento dos artigos de periódicos foi realizado em consulta às bases de dados on-line LIBES, BRAPCI, ScIELO e Google Acadêmico. Buscou-se por meio da análise dos textos, identificar a aplicabilidade da Lei, no sentido de verificar os avanços, as perspectivas e as limitações da mesma. Complementa-se o artigo com a descrição das ações realizadas pelos órgãos de classe catarinense no sentido de fazer cumprir a Lei $\mathrm{n}^{0}$ 12.244/2010. A análise dos textos poderão subsidiar as futuras interlocuções e contribuir na condução de um debate mais efetivo nas diferentes esferas políticas do Estado para o cumprimento da referida Lei.
\end{abstract}

Palavras Chave: Biblioteca Escolar. Bibliotecário Escolar. Lei nº12.244/2010. CRB-14.

\section{INTRODUÇÃO}

Biblioteca, Sala de Leitura, Sala de Estudos, Centro de Recursos de Aprendizagem e outras denominações. O nome utilizado não interfere no seu papel: auxiliar no processo ensino-aprendizagem. A biblioteca é multidisciplinar. Promover eventos, participar das atividades extracurriculares da escola, elaborar exposições e concursos, tudo é válido para atrair o público, principalmente jovem, da

\footnotetext{
${ }^{1}$ Graduado em Biblioteconomia e Administração pela Universidade do Estado de Santa Catarina (UDESC).

${ }^{2}$ Graduada em Biblioteconomia pela Universidade do Estado de Santa Catarina (UDESC).

3 Mestre em Biblioteconomia pela Pontifícia Universidade Católica de Campina (PUCCAMP).
} 
Revista ACB: Biblioteconomia em Santa Catarina, Florianópolis, v. 22, n. 2, ESPECIAL, p. 161-179, abr./ jul., 2017. Anais do $35^{\circ}$ Painel Biblioteconomia Santa Catarina.

Chapecó

comunidade escolar. A interação com os livros, e, por consequência, o desenvolvimento da leitura, ocorre de maneira espontânea e natural a partir do momento em que o estudante percebe que a biblioteca é um espaço aberto e amigável, que oferece recursos e atividades diversos.

A biblioteca escolar é um local privilegiado, que auxilia na interação dos professores com os bibliotecários, permitindo um trabalho em conjunto para desenvolver a autonomia e independência na leitura. Seu espaço, ambiente e acervo devem promover a leitura e responder com exatidão às necessidades da comunidade educacional. E o profissional bibliotecário precisa entender seu papel neste processo, atuando em sintonia com o setor pedagógico, contribuindo, assim, para a formação de leitores.

Muitos questionam o papel da biblioteca na era digital, porém é necessário compreender que "um grande número de brasileiros só tem acesso a livros e outras fontes/recursos de leitura na biblioteca" (BICHERI; ALMEIDA JUNIOR, 2013, p.42). Além disso, a informatização das informações amplia, sim, as oportunidades para uma parte da população, porém, “cria também, para outra maior ainda, mais um abismo - o da exclusão do impresso e do digital" (MOLLO; NÓBREGA, 2011, p.8). Por isso, a presença da biblioteca nas escolas é essencial e a mesma precisa fazer parte do projeto pedagógico da escola, atendendo a demanda dos usuários, sejam elas digitais ou impressas.

Certamente somente o espaço físico, sua decoração e seu acervo não são suficientes para que o processo ocorra. Para exercer suas funções e cumprir com seus objetivos, a biblioteca precisa de um profissional habilitado, sensível e competente que participe da escola como um todo, através das reuniões pedagógicas e das atividades curriculares. O bibliotecário escolar deve, então, possuir qualidades específicas e estar engajado no processo pedagógico por inteiro.

O bibliotecário não pode mais se esconder no estereótipo passivo, quietinho, esperando os usuários, ou entre as estantes guardando os livros. O bibliotecário escolar precisa interagir com seus usuários, ser dinâmico. De modo a desempenhar sua função de educador dentro da escola, o mesmo precisa adotar uma postura pró-ativa diante das dificuldades, realizar com rigor o trabalho técnico e ter consciência de seu papel de mediador, agente cultural, formador de leitores etc.

Afinal, os educadores reconhecem o papel e a importância da biblioteca escolar, porém desconhecem, ou discordam, sobre a importância do bibliotecário na escola. Muitos ainda acreditam que este profissional não é competente para participar das atividades pedagógicas. Equivocadamente acreditam que o bibliotecário é um profissional totalmente técnico, que não sabe, não pode e não deve se envolver no processo ensino/pedagógico. "Ao bibliotecário escolar não bastam conhecimentos técnicos da área de biblioteconomia, educação e leitura. Ele precisa se envolver com sua comunidade, saber e gostar de trabalhar com crianças, adolescentes e adultos.” (BICHERI; ALMEIDA JUNIOR, 2013, p.44). Revista ACB: Biblioteconomia em Santa Catarina, Florianópolis (Brasil) - ISSN 1414-0594 
Revista ACB: Biblioteconomia em Santa Catarina, Florianópolis, v. 22, n. 2, ESPECIAL, p. 161-179, abr./ jul., 2017. Anais do $35^{\circ}$ Painel Biblioteconomia Santa Catarina.

Chapecó

Existem inúmeras atividades que podem fazer parte do ano letivo na biblioteca. Hora do conto, exposições, concursos literários, divulgação de acervo, recomendação de leitura (do bibliotecário e dos alunos), varal de poesias entre outras. Com planejamento e criatividade, utilizando-se dos recursos disponíveis, o bibliotecário consegue desenvolver uma série de atividades que podem facilitar o reconhecimento do espaço "biblioteca" e do profissional atuante no local.

Entretanto, a biblioteca escolar ainda é um mito em muitas escolas públicas brasileiras. Na prática descobrimos muitas escolas sem biblioteca, e quando existe, muitas vezes, está em situação precária e não conta com a presença do bibliotecário. Sendo este um espaço obsoleto, que não desempenha seu papel de interação educacional e não oferece, assim, condições para o desenvolvimento das atividades mencionadas acima e que auxiliariam no trabalho de incentivo a leitura e formação de leitores.

A rede particular de ensino já apresenta uma iniciativa maior a respeito das bibliotecas escolares, porém ainda se faz necessário a conscientização do papel do bibliotecário no processo de transformação do espaço e valor agregado à biblioteca escolar.

Muitas vezes encontramos professores em desvio de função e, até, funcionários administrativos ocupando o lugar do bibliotecário. Porém não podemos deixar de mencionar que existe, em alguns casos, um despreparo do profissional bibliotecário para atuar num ambiente pedagógico, fazendo com que a biblioteca não se faça presente no dia-a-dia da escola. O bibliotecário escolar, mais do que nunca, deve ser multidisciplinar. E a biblioteca, um espaço alegre, criativo, disponível e aberto a descobertas e reflexões, proporcionando então, autonomia no pensar das crianças e adolescentes.

Com a promulgação da Lei 12.244/2010, que dispõe sobre a universalização das bibliotecas nas escolas brasileiras, determinando que todas as escolas brasileiras de ensino básico disponham de uma biblioteca até o ano de 2020, podemos almejar mudanças no cenário escolar e no reconhecimento da biblioteca e do profissional bibliotecário. De acordo com Fragoso (2011, p.14), “[A promulgação] amplia o horizonte das bibliotecas e estabelece amparo legal para criação de bibliotecas com espaço físico adequado, acervo selecionado e adquirido, levando em conta as prioridades da comunidade escolar [...]”.

Nessa linha, definiu-se como objetivo geral desta pesquisa, analisar as reações à promulgação da Lei n. ${ }^{\circ}$ 12.244/2010, ponderando seus avanços, perspectivas e limitações. Definiu-se como objetivos específicos: i. Identificar os artigos de periódicos oriundos do meio acadêmico e profissional, publicados a partir da promulgação da Lei n. ${ }^{0}$ 12.244/2010; ii. Descrever as ações dos órgãos de classe do Estado de Santa Catarina com vistas à aplicabilidade da Lei n. ${ }^{0}$ 12.244/2010.

Revista ACB: Biblioteconomia em Santa Catarina, Florianópolis (Brasil) - ISSN 1414-0594 
Revista ACB: Biblioteconomia em Santa Catarina, Florianópolis, v. 22, n. 2, ESPECIAL, p. 161-179, abr./ jul., 2017. Anais do $35^{\circ}$ Painel Biblioteconomia Santa Catarina.

Chapecó

\section{METODOLOGIA}

Com a finalidade de analisar a presença do termo "Lei n ${ }^{\circ}$ 12.244/2010" nos artigos de periódicos, foi realizado o levantamento bibliográfico nas seguintes bases de dados disponíveis na Internet: LIBES Literatura Brasileira em Biblioteca Escolar, mantida pelo Grupo de Estudos em Biblioteca Escolar da Escola de Ciência da Informação da Universidade Federal de Minas Gerais; BRAPCI - Base Referencial de Revistas de Biblioteconomia e Ciência da Informação, desenvolvida e mantida pela Universidade Federal do Paraná; SciELO - A Scientific Electronic Library Online, biblioteca eletrônica de periódicos científicos brasileiros, desenvolvida pela Fundação de Amparo à Pesquisa do Estado de São Paulo, FAPESP em parceria com outras instituições; e Google Acadêmico, um sistema do Google que oferece ferramentas específicas para que os pesquisadores busquem e encontrem literatura acadêmica disponíveis na web.

Foram identificados, pelo levantamento nas bases de dados on-line, 14 (quatorze) artigos de periódicos. Os mesmos retratam a produção científica sobre o tema, a partir da promulgação da Lei ${ }^{\circ}$ 12.244/2010, e formam o corpus de análise do presente estudo. Os artigos analisados constam no item Referências.

Na metodologia utilizou-se a análise textual de documentos que citaram a Lei a partir de sua promulgação em maio de 2010. A busca foi realizada a partir do descritor "Lei n ${ }^{\circ} 12.244 / 2010$ ”, presente nos seguintes filtros: título, resumo e descritores. Severino (2007) apresenta uma metodologia para o estudo de textos que compreende três etapas: análise textual, a análise temática e a análise interpretativa. A análise textual é a primeira forma de aproximação do leitor com o texto, por meio do qual o pensamento do autor será conhecido, ou seja, estudando as ideias e o pensamento do autor de uma maneira clara e objetiva, dando ênfase as partes essenciais do texto. A análise textual visa a preparação das etapas subsequentes, que são a análise temática e a análise interpretativa, porém não foram utilizadas nesta pesquisa.

Para descrever as ações dos órgãos de classe do Estado de Santa Catarina com vistas à aplicabilidade da Lei n. ${ }^{\circ}$ 12.244/2010, foi consultado o Relatório de Atividades do Conselho Regional de Biblioteconomia $14^{\mathrm{a}}$ Região, uma vez que as atividades relacionadas à aplicabilidade da referida lei foram realizadas conjuntamente com a Associação Catarinense de Bibliotecários e as instituições de ensino superior que oferecem o curso de graduação em Biblioteconomia, em Santa Catarina.

Revista ACB: Biblioteconomia em Santa Catarina, Florianópolis (Brasil) - ISSN 1414-0594 
Revista ACB: Biblioteconomia em Santa Catarina, Florianópolis, v. 22, n. 2, ESPECIAL, p. 161-179, abr./ jul., 2017. Anais do $35^{\circ}$ Painel Biblioteconomia Santa Catarina.

Chapecó

\section{APLICABILIDADE DA LEI No 12.244/2010: ANÁLISE DA LITERATURA BRASILEIRA}

No levantamento bibliográfico realizado para identificar os artigos de periódicos publicados a partir da promulgação da Lei n. ${ }^{\circ}$ 12.244/2010, nos deparamos com a pesquisa de Campello et al. (2016) e que, devemos reconhecer, norteou nossa pesquisa. Campello et al. (2016) analisou as manifestações sobre a Lei n. ${ }^{\circ}$ 12.244/2010, originadas do meio acadêmico e profissional, considerando os artigos de periódicos e as manifestações da sociedades nas redes sociais (Internet). Destaca-se, com relação às publicações oriundas do meio acadêmico e profissional, embora em pequeno número, que as mesmas abordaram "uma gama de aspectos que esclareceram as principais questões relativas à Lei e que podem contribuir na condução de um debate mais efetivo para a aplicação da Lei nas escolas" (CAMPELLO et al., 2016, p. 54), a saber: i. A lei não assume o conceito de Biblioteca Escolar aceito pela comunidade acadêmica e pelas organizações que se preocupam com o caráter educativo da biblioteca como espaço de aprendizagem; ii. Há uma preocupação dos autores em ressaltar a responsabilidade do bibliotecário para garantir a biblioteca como espaço de aprendizagem; iii. O acervo é o foco da lei, pois ela o dimensiona em termos de quantidade, isto é, um título por aluno e diversidade, pois não limita a quantidade de exemplares de um mesmo título; iv. A responsabilidade pela ampliação, manutenção, preservação e organização é encaminhada para os sistemas locais, sendo que esta responsabilidade é pouco clara, não se prevendo recursos e nem punições em caso de seu não cumprimento.

Em outro artigo, Campello (2015) analisou textualmente documentos selecionados entre aqueles que apresentam dados estatísticos, e estudos críticos e avaliativos sobre as bibliotecas escolares brasileiras. A pesquisa apresentou um panorama da situação das bibliotecas escolares do Brasil e as questões que afetam o seu desenvolvimento. Dois pontos emergiram da análise: i. O surgimento de Grupos de Pesquisa Acadêmica desde a década de 1990 e o consequente aumento dos estudos sobre biblioteca escolar, o que indica que a base teórica para a melhoria das bibliotecas escolares está sendo construída; ii. A necessidade de comprovação da eficácia da promulgação da Lei n. ${ }^{0}$ 12.244/2010, mesmo essa representando uma grande conquista.

Dos 14 (quatorze) artigos analisados, quatro são diagnósticos que utilizaram o questionário e a entrevista para coletar informações das Bibliotecas Escolares sobre: acervo, serviços oferecidos, recursos humanos, espaço físico, mobiliários, aspectos administrativos e financeiros, e comunidade de usuários. Esses quatro diagnósticos foram realizados a partir do que rege a Lei n. ${ }^{\circ}$ 12.244/2010, a saber: Coppola Junior e Castro Filho (2012), Moreno (2014), Chagas (2016) e Vahldick (2017).

Revista ACB: Biblioteconomia em Santa Catarina, Florianópolis (Brasil) - ISSN 1414-0594 
Revista ACB: Biblioteconomia em Santa Catarina, Florianópolis, v. 22, n. 2, ESPECIAL, p. 161-179, abr./ jul., 2017. Anais do $35^{\circ}$ Painel Biblioteconomia Santa Catarina.

Chapecó

O objetivo da pesquisa de Coppola Junior e Castro Filho (2012) foi conhecer a situação das Bibliotecas Escolares da rede de ensino municipal em Ribeirão Preto (SP) com vista à elaboração de um modelo de biblioteca escolar para implantação nas escolas municipais de ensino fundamental do mesmo município. A pesquisa foi realizada em duas partes: i. Pesquisa bibliográfica sobre o tema "biblioteca escolar"; ii. Aplicação de um questionário para coleta de informações, tendo em vista a Lei n. ${ }^{\circ}$ 12.244/2010, encaminhado para quarenta estudantes universitários de Ribeirão Preto, com as seguintes perguntas:

a) A escola onde você estudava, durante o ensino fundamental, era pública ou privada? b) $\mathrm{Na}$ sua escola existia biblioteca escolar? Se sim, quem era o responsável (cargo)? c) Você frequentava a biblioteca escolar de sua escola? Ou outro tipo de biblioteca (pública ou universitária)? d) Na sua opinião qual a importância da Biblioteca Escolar, para os alunos e a escola? (COPPOLA JUNIOR; CASTRO FILHO, 2012, p. 5)

A pesquisa de Moreno (2014) teve como objetivo realizar o diagnóstico das bibliotecas escolares da rede de ensino fundamental do município de Jaraguá do Sul (SC), a partir do que rege a Lei n. $^{\circ}$ 12.244/2010. As informações sobre os recursos materiais e humanos, acervo e serviços foram coletadas com a utilização de um questionário considerando os aspectos inerentes a Lei em questão e estudos já realizados sobre bibliotecas escolares. O mesmo foi aplicado em 10 escolas da rede municipal de ensino, constatando-se que todas possuem bibliotecas como determina a Lei n. ${ }^{\circ} 12.2444$. Porém, existem outros fatores que precisam ser considerados como: a inserção do bibliotecário no cenário escolar; o planejamento da estrutura física e de mobiliário das bibliotecas para oferecer uma biblioteca de qualidade à comunidade escolar. Mesmo constatado que as mesmas se adéquam a Lei, por possuir Biblioteca e o número mínimo de acervo exigido pela lei, existe uma lacuna entre o "ideal” pretendido pela literatura da área.

O tema da pesquisa de Chagas (2016) foi verificar se as bibliotecas escolares, de uma cidade do estado de Goiás, atendem a Lei n ${ }^{0}$ 12.244/2010 e as diretrizes da UNESCO/IFLA, referente ao acervo, à organização e ao pessoal para atendimento da comunidade estudantil. Os instrumentos utilizados para a coleta de dados foram a observação, a entrevista e os registros fotográficos. Constatou-se que a problemática da Biblioteca Escolar continua a mesma nas últimas décadas do século passado: espaço insuficiente e inadequado. $\mathrm{O}$ acervo insuficiente e desatualizado formado, em sua maioria, por livros didáticos distribuídos pelo governo federal guardados na Biblioteca. Com relação aos recursos humanos, observa-se a presença de funcionários em desvio de função, sem formação específica, permanecendo o silêncio consentido, pouco funcional para o ensino e a aprendizagem.

Revista ACB: Biblioteconomia em Santa Catarina, Florianópolis (Brasil) - ISSN 1414-0594 
Revista ACB: Biblioteconomia em Santa Catarina, Florianópolis, v. 22, n. 2, ESPECIAL, p. 161-179, abr./ jul., 2017. Anais do $35^{\circ}$ Painel Biblioteconomia Santa Catarina.

Chapecó

A pesquisa mais recente, de Vahldick (2017), teve como objetivo diagnosticar as bibliotecas escolares da rede municipal de ensino de Indaial (SC) para, posteriormente, elaborar um plano de melhoria com base nas diretrizes da UNESCO/IFLA e a Lei $n^{0}$ 12.244/2017. Foram utilizados questionários, entrevistas e observação in loco em oito bibliotecas escolares. Os autores deram início ao projeto em 2006, com um estudo preliminar, e constataram melhorias, desde então, relacionadas à estrutura física, ao acervo, ao horário de atendimento, ao número de funcionários para atendimento e à realização de atividades de incentivo à leitura. Porém, as mesmas ainda não oferecem computadores ou acesso à Internet e, principalmente, não contam com profissional bibliotecário.

Além dos quatro diagnósticos mencionados, outros autores se referem ao assunto. O artigo de Silva (2011) trata da história da biblioteca escolar no Brasil e analisa as perspectivas históricas, sociais e semânticas da biblioteca escolar, tendo como enfoque a Lei $\mathrm{n}^{0} 12.244 / 2010$, a partir de uma pesquisa exploratória, com revisão documental. E conclui que, a biblioteca escolar, historicamente, esteve diretamente ligada às instituições religiosas, como os colégios jesuítas, franciscanos, beneditinos e carmelitas, e hoje, com a institucionalização da Lei n. ${ }^{\circ}$ 12.244/10, mostra uma conotação de mudança. Porém, entende-se que a referida Lei apresenta deficiências conceituais e conteudísticas, quanto à caracterização da biblioteca escolar e suas nuances de acervo, assim como deficiências que promovem insegurança quanto à sua consolidação, por não prever perspectivas de responsabilidades compulsórias, ou seja, de punições no caso do não cumprimento, por parte das escolas públicas e privadas, daquilo que nela é estabelecido.

Araújo (2015) discorre em seu artigo sobre as Leis discutidas, votadas ou por votar no contexto atual pelo Legislativo brasileiro acerca do tema da biblioteca escolar, com especial atenção para a Lei ${ }^{\circ}$ 12.244/2010. Valeu-se para essa pesquisa das fontes de pesquisa legislativas oficiais, como os sites do Planalto, da Câmara e do Senado. Dentre as críticas apontadas pelo autor, destaca-se que os esforços ainda parecem ser desconexos da realidade, uma vez que se tenta implementar, de cima para baixo, o que a comunidade, embora necessitada, não se preparou para assumir. Para Araujo (2015, p. 35),

O que deve ser prezado são antes as condições básicas de educação. Quando as escolas atingirem condições adequadas de funcionamento, a biblioteca escolar se dará de forma automática, pois não se pode pensar uma educação de excelência que prescinda da biblioteca.

A pesquisa de Braga e Paula (2014) teve o objetivo de analisar a representação educativa da biblioteca inserida no contexto escolar, descrevendo o conceito de Biblioteca Escolar, sua função e missão, a partir da aprovação da Lei $\mathrm{n}^{0}$ 12.244/2010. Com base nas análises realizadas pode-se inferir que, com relação à biblioteca escolar, uma de suas principais funções é auxiliar e complementar o Revista ACB: Biblioteconomia em Santa Catarina, Florianópolis (Brasil) - ISSN 1414-0594 
Revista ACB: Biblioteconomia em Santa Catarina, Florianópolis, v. 22, n. 2, ESPECIAL, p. 161-179, abr./ jul., 2017. Anais do $35^{\circ}$ Painel Biblioteconomia Santa Catarina.

Chapecó

processo de ensino-aprendizagem e se encaixar na qualidade de função educativa. Necessitando, porém ampliar o escopo para se integrar à sala de aula e ao desenvolvimento do currículo pedagógico escolar. Destaca-se, ainda, a importância de inserir o bibliotecário conforme previsto na Lei $\mathrm{n}^{\mathrm{o}}$ 12.244/2010.

O objetivo do artigo de Ferrarezi e Sousa (2014) foi investigar, a partir do olhar da análise do discurso de linha francesa, os efeitos de sentidos suscitados pelas políticas públicas que historicamente vêm sendo destinadas às bibliotecas escolares brasileiras, destacando-se a falta e o equívoco que os constituem. $\mathrm{O}$ artigo apresenta algumas considerações sobre a teoria discursiva que embasa a pesquisa. Faz uma breve análise da Lei $\mathrm{n}^{\mathrm{o}}$ 12.244/2010, perscrutando os sentidos de biblioteca escolar nela circulantes.

Entretanto, dentre os artigos analisados nesta pesquisa, destacamos os de Campello et al. (2011), de Fragoso (2011), de Castro Filho e Coppola Junior (2012), e de Garcez et al. (2016) como os mais significativos e que apresentam maior contribuição na condução de um debate mais efetivo para a aplicação da Lei $n^{0} 12.244 / 2010$ no país.

Campello et al. (2011), descrevem o processo de elaboração dos padrões para as bibliotecas escolares brasileiras, com a descrição dos princípios, referenciais teóricos e critérios que os embasaram. O objetivo dos padrões é apoiar as escolas no processo de implementação da Lei $\mathrm{n}^{0} 12.244 / 2010$. Os padrões visam a complementar a Lei e contribuir para que cada comunidade escolar possa estabelecer o perfil da biblioteca de sua escola. Para os autores em questão, “os padrões contribuirão para que o processo de universalização das bibliotecas nas escolas do país se dê com qualidade, ou seja, para que cada escola conte com uma biblioteca de verdade".

Fragoso (2011) apresenta as orientações a respeito do que vem a ser uma biblioteca escolar: o espaço físico, o acervo e sua organização, o acesso à internet, os serviços e atividades e a qualificação do pessoal, na série "Salto para o Futuro", onde foi dedicado um número especial para tratar do tema “Biblioteca escolar: que espaço é esse?”, com discussões, de diversos autores, sobre a Biblioteca Escolar, a partir da promulgação da Lei ${ }^{\circ} 12.244 / 2010$, em um momento em que a tecnologia, particularmente computadores conectados à Internet, permite o acesso a uma imensa variedade de fontes.

A pesquisa de Castro Filho e Coppola Junior (2012) foi realizada através de análise documental e levantamento bibliográfico. Nela os autores apresentam um modelo de biblioteca escolar, a ser implantado nas escolas de ensino fundamental no município de Ribeirão Preto (SP), criado a partir de diretrizes já existentes no que tange a infraestrutura, o mobiliário, os equipamentos eletrônicos, as sinalizações, o acervo etc., além disso, determinam os objetivos e serviços da biblioteca escolar.

Revista ACB: Biblioteconomia em Santa Catarina, Florianópolis (Brasil) - ISSN 1414-0594 
Revista ACB: Biblioteconomia em Santa Catarina, Florianópolis, v. 22, n. 2, ESPECIAL, p. 161-179, abr./ jul., 2017. Anais do $35^{\circ}$ Painel Biblioteconomia Santa Catarina.

Chapecó

Garcez et al. (2016), apresenta um projeto de rede de Bibliotecas para as escolas públicas estaduais de Santa Catarina, Brasil. Além de descrever os percursos da implantação de uma rede, aborda a possibilidade de criação do cargo de bibliotecário vinculado ao Quadro do Magistério Público do Estado. $\mathrm{O}$ artigo discute a Biblioteca Escolar do Estado de Santa Catarina na agenda governamental ao longo do século XX e os questionamentos de suas ações no século XXI. Discorre ainda sobre os percalços e os avanços no processo de construção do projeto em questão. Expõe as intenções que levou o grupo a conceber o projeto para a Rede de Bibliotecas e criação do cargo de Bibliotecário. E, finalmente, destaca a importância de se estabelecer interlocuções nas diferentes esferas políticas e de socializar esse projeto entre as bibliotecas escolares visando seu conhecimento e discussão.

\section{LEI 12.244/2010: AVANÇOS, PERSPECTIVAS E LIMITAÇÕES}

Como resultado da análise textual dos artigos de periódicos selecionados, e publicados a partir da promulgação da Lei $\mathrm{n}^{0} 12.244 / 2010$, os assuntos foram agrupados em quatro itens, na expectativa de elencar os avanços, perspectivas e limitações da referida Lei, a saber: i. Produção cientifica; ii. Sistema educacional e a Lei 12.244; iii. Biblioteca escolar, e iv. Bibliotecário.

\subsection{Produção Científica}

Observa-se que houve um crescimento significativo de artigos de periódicos publicados a partir da promulgação da Lei 12.244/2010 que passou de três artigos analisados na pesquisa, de Campello et al. (2016), para 14 (quatorze) artigos de periódicos originados do meio acadêmico e profissional. Destes, cinco artigos foram publicados no periódico "Biblioteca Escolar em Revista" de Ribeirão Preto, que concentrou 35,71\% da produção. Dois artigos foram publicados na "Revista ACB: Biblioteconomia em Santa Catarina" e os demais artigos (sete) foram publicados em diversos títulos de periódicos.

Dentre os artigos analisados destaca-se a contribuição da publicação: "Biblioteca escolar como espaço de produção do conhecimento: parâmetros para bibliotecas escolares” (CAMPELLO, 2010). Este documento é reconhecido pelo Conselho Federal de Biblioteconomia (CFB), por meio da Resolução CFB $n^{\circ} 119 / 2011$, como um instrumento que irá apoiar as escolas no processo de implementação da Lei $n^{\circ}$ 12.244/2010, por apresentar os critérios a serem observados no estabelecimento do perfil da biblioteca de cada escola e possa contar com uma Biblioteca de verdade.

Outro fator que contribui para o aumento da quantidade e qualidade das publicações sobre Biblioteca Escolar é, segundo Campello (2015), o surgimento de Grupos de Pesquisa Acadêmica desde a

Revista ACB: Biblioteconomia em Santa Catarina, Florianópolis (Brasil) - ISSN 1414-0594 
Revista ACB: Biblioteconomia em Santa Catarina, Florianópolis, v. 22, n. 2, ESPECIAL, p. 161-179, abr./ jul., 2017. Anais do $35^{\circ}$ Painel Biblioteconomia Santa Catarina.

Chapecó

década de 1990, e o consequente aumento dos estudos sobre biblioteca escolar, que indicam que a base teórica para a melhoria dessas instituições está sendo construída.

\subsection{Sistema Educacional e a Lei 12.244/2010}

A responsabilidade pela ampliação, manutenção, preservação e organização é encaminhada para os sistemas locais, sendo que esta responsabilidade é pouco clara, não se prevendo recursos e nem punições em caso de seu não cumprimento, segundo Campello et al. (2016). Silva (2011) também aponta as deficiências da Lei n. ${ }^{\circ}$ 12.244/2010, que promove insegurança quanto à sua consolidação e o fato de não prever perspectivas de responsabilidades compulsórias, ou seja, de punições no caso do não cumprimento por parte das escolas públicas e privadas, daquilo que nela é estabelecido.

De acordo com Castro Filho e Coppola Junior (2012),

Legislação específica, diretrizes e padrões já representam uma realidade para a implantação das bibliotecas escolares, no entanto, o agir dos responsáveis pela educação e o envolvimento da comunidade escolar consolidará essa conquista [...], possibilitando a milhares de crianças e adolescentes o acesso à informação, cultura e cidadania.

Segundo Campello (2015), a promulgação, da Lei 12.244, representa uma grande conquista, mas sua eficácia ainda precisa ser comprovada.

Castro Filho e Coppola Junior (2012) afirmam, ainda, que:

A Lei n. ${ }^{\circ}$ 12.244/2010 representa um dos maiores avanços, no sentido do Estado se posicionar frente ao Manifesto da IFLA/UNESCO para Biblioteca Escolar. Porém, cabe à comunidade escolar, aos professores, aos bibliotecários, reivindicar a aplicação desta lei, de forma a impedir que seja esquecida e suprimida por outros interesses.

Para Araújo (2015, p.35), o que deve ser prezado são, antes, as condições básicas de educação: "quando as escolas atingirem condições adequadas de funcionamento, a biblioteca escolar se dará de forma automática, pois não se pode pensar uma educação de excelência que prescinda da biblioteca”.

Garcez et al. (2016) apresenta um projeto de Rede de Bibliotecas para as escolas públicas estaduais do Estado de Santa Catarina e destaca a importância de se estabelecer interlocuções nas diferentes esferas políticas e de socializar esse projeto entre as bibliotecas escolares, para que possa ser conhecido e discutido.

\subsection{Biblioteca Escolar}

“A Lei não assume o conceito de Biblioteca Escolar aceito pela comunidade acadêmica e pelas organizações que se preocupam com o caráter educativo da biblioteca como espaço de aprendizagem" 
Revista ACB: Biblioteconomia em Santa Catarina, Florianópolis, v. 22, n. 2, ESPECIAL, p. 161-179, abr./ jul., 2017. Anais do $35^{\circ}$ Painel Biblioteconomia Santa Catarina.

Chapecó

(CAMPELLO et al., 2016) e ignora o avanço das pesquisas já existentes sobre o tema como a UNESCO, IFLA e Conselho Federal de Biblioteconomia. Os autores ainda afirmam que:

O acervo é o foco da lei, pois ela o dimensiona em termos de quantidade e diversidade. A definição de um título por aluno é positiva, pois significa que a coleção terá maior diversidade de obras, não sendo suficiente que haja muitos exemplares de um mesmo título. Indiretamente isso contribui para reforçar a noção de que o livro didático para uso do aluno não é material do acervo da biblioteca.

Para Braga e Paula (2014), fica comprovado que uma das principais funções da biblioteca escolar é “auxiliar e complementar o processo de ensino aprendizagem" e se encaixa na qualidade de função educativa, necessitando, porém ampliar o escopo para se integrar à sala de aula, no desenvolvimento do currículo pedagógico escolar.

\subsection{Bibliotecário}

Há uma preocupação dos autores em ressaltar a responsabilidade do bibliotecário para garantir a biblioteca como espaço de aprendizagem. "O fato é que há uma clareza de que a Lei não pode servir apenas para garantir que haja uma biblioteca em cada escola; esses espaços precisam ser qualificados. Acredita-se que é a presença do bibliotecário que garantirá essa qualidade”. (CAMPELLO et al., 2016)

No pronunciamento do SINTE/SC, “apesar da importância de ser implementada e regulamentada nos estados e municípios a Lei 12.244 não prevê as formas de ter o bibliotecário nas bibliotecas das escolas" revela um possível indício de que há dúvidas na administração pública de estados e municípios quanto à aplicação dessa Lei. (GARCEZ et al., 2016)

É importante que os bibliotecários brasileiros percebam a importância da publicação "Biblioteca escolar como espaço de produção do conhecimento: Parâmetros para bibliotecas escolares" como um instrumento inovador para criar e aperfeiçoar bibliotecas escolares que sejam verdadeiramente espaços de aprendizagem contribuindo para a melhoria da qualidade das bibliotecas escolares brasileiras. (CAMPELLO et al., 2016)

\section{AÇÕES DOS ÓRGÃOS DE CLASSE DO ESTADO DE SANTA CATARINA}

São, aqui, descritas as ações conjuntas do Conselho Regional de Biblioteconomia 14ª Região (CRB14), da Associação Catarinense de Bibliotecários (ACB), dos cursos de graduação em Biblioteconomia da Universidade do Estado de Santa Catarina (UDESC) e da Universidade Federal de Santa Catarina (UFSC), e do Grupo de Bibliotecários da Área Escolar (GBAE/SC) na divulgação da Lei nº 12.244/2010, 
Revista ACB: Biblioteconomia em Santa Catarina, Florianópolis, v. 22, n. 2, ESPECIAL, p. 161-179, abr./ jul., 2017. Anais do $35^{\circ}$ Painel Biblioteconomia Santa Catarina.

Chapecó

visando a conscientização e interlocuções com os gestores estaduais e municipais para a importância da aplicação da referida Lei, com base nos Relatórios Anuais de Atividades do CRB-14.

\subsection{Interlocução com a Secretaria de Estado da Educação}

Em 2003 a Secretaria de Estado da Educação pública a Portaria nº. 003/SED, que designava professores excedentes e readaptados como responsáveis por Bibliotecas, Laboratórios de Informática e outras áreas fundamentais da escola, com o objetivo de minimizar esta situação e, por outro lado, apontar para a necessidade da ativação destes espaços. A publicação dessa Portaria, mais o programa de estágio "A Primeira Chance", que oportuniza aos alunos de segundo grau e universitários, atuar nas Bibliotecas Escolares do Estado, sem a supervisão do Bibliotecário, em desacordo com a Lei no 4.084/62, que dispõe sobre a profissão do bibliotecário, foram os dois motivos que mobilizaram a classe biblioteconômica de Santa Catarina para iniciar a negociação com a Secretaria de Estado da Educação. Formou-se uma comissão com representantes das entidades de classe do Estado que apresentaram à Secretaria de Estado da Educação um projeto que levou em consideração a impossibilidade de contar com um bibliotecário em cada escola estadual. Por esta razão, previa uma articulação entre o Bibliotecário lotado na Secretaria de Estado da Educação com os bibliotecários lotados nas Secretarias de Estado do Desenvolvimento Regional (SDRs), além de Bibliotecários nas unidades escolares com maior número de alunos matriculados. A partir da intervenção da categoria bibliotecária, mais uma vez o Governo acenou para a possibilidade de transformar 300 cargos de Assistente Educacional do Plano de Cargos e Salários do Magistério em cargos de Bibliotecário.

\subsection{Projeto de Lei para criação do Cargo de Bibliotecário nas Escolas}

Paralelamente às interlocuções da classe bibliotecária com a Secretaria de Estado da Educação, tramitava na Assembleia Legislativa, por iniciativa do Poder Legislativo, o Projeto de Lei Complementar PLC/0039.0 de 20 de julho de 2010, que objetivou criar o Cargo de Bibliotecário para atuar nas escolas públicas estaduais. Nesse PLC era prevista a alteração da Lei $n^{\circ} 1.139 / 1992$, que dispõe sobre Cargos e Carreiras do Magistério Público Estadual, incluindo nela o Cargo de Bibliotecário. Vê-se que a ideia de iniciativa do Executivo, de vincular o cargo de Bibliotecário ao Quadro do Magistério, ocorrida em 2003, é aqui retomada. Neste momento, a classe se mobilizou para apresentar, anexo ao projeto, um abaixo assinado da população com número altíssimo de assinaturas. Apesar de aprovado na Assembleia Revista ACB: Biblioteconomia em Santa Catarina, Florianópolis (Brasil) - ISSN 1414-0594 
Revista ACB: Biblioteconomia em Santa Catarina, Florianópolis, v. 22, n. 2, ESPECIAL, p. 161-179, abr./ jul., 2017. Anais do $35^{\circ}$ Painel Biblioteconomia Santa Catarina.

Chapecó

Legislativa, o PLC/0039.0/2010 foi posteriormente declarado inconstitucional por tratar de “[...] matéria de iniciativa exclusiva do Governador do Estado, a quem compete iniciar o processo legislativo." A esse argumento pela inconstitucionalidade juntou-se outro: sem a anuência prévia do Governo o projeto teria problemas de orçamento no Executivo. (GARCEZ et al., 2016)

\subsection{Projeto de Rede de Bibliotecas para as Escolas Públicas Estaduais}

Em 2012, por conta da publicação da Lei $n^{\circ}$ 12.244/2010 e pela presença do bibliotecário na equipe de gestão da Secretaria de Estado da Educação, as discussões são retomadas por meio de uma comissão com representantes das entidades de classe incumbida de estudar e apresentar uma proposta ao Executivo. Essa comissão, representativa dos bibliotecários, resgatou o que a categoria tinha, até então, discutido e reunido em documentos. Do que havia, permaneceu a vinculação do cargo de Bibliotecário ao Quadro do Magistério, a alterar a Lei $\mathrm{n}^{\circ}$ 1.139/1992, e o quantitativo de 300 cargos. A reestruturação ficou por conta de um modelo de Rede de Bibliotecas (prevendo-se a distribuição do bibliotecário nela com um rol de atribuições específicas), e a implementação de quadro salarial e de carreira. Na reestruturação, a grande novidade deu-se pela distribuição dos 300 cargos em três distintas áreas de atuação profissional: i. Unidade Central da Secretaria de Estado da Educação (SED); ii. Secretarias de Desenvolvimento Regional (SDR) - unidades descentralizadas do Executivo, ou nas 37 Gerências Regionais de Educação (GEREI) - unidades setoriais da SED; e, iii. Unidades escolares distribuídas em 293 municípios.

Esse modelo de Rede apresentado à Secretaria de Educação, no início de 2013, foi publicado no periódico brasileiro Perspectivas em Ciência da Informação em 2016. O artigo descreve as atribuições do bibliotecário agrupadas em conformidade com os três locais que esse profissional poderá atuar, definindo as funções de: gestão, técnica e técnica-pedagógica, que são, segundo Garcez et al. (2016):

Bibliotecário na Escola: Desenvolve atividades de incentivo à leitura, de difusão e disseminação de informações nas unidades escolares, envolvendo-se com as questões curriculares e extracurriculares da escola, e atendendo também a comunidade local;

Bibliotecário na Secretaria de Estado da Educação: Participa do planejamento das decisões da Secretaria de Estado da Educação voltadas às políticas de leitura e uso da informação nas escolas. Mantém estreita interlocução com os bibliotecários lotados nas Secretarias de Desenvolvimento Regional (SDR) e nas Gerências Regionais de Educação (GERED) e, por intermédio destes, com os que atuam nas escolas sendo seu representante na Secretaria.

Bibliotecário nas Secretarias de Estado de Desenvolvimento Regional e nas Gerências Regionais de Educação: Trabalha em parceria com os profissionais da SDR/GERED. Assessora, no que Revista ACB: Biblioteconomia em Santa Catarina, Florianópolis (Brasil) - ISSN 1414-0594 
Revista ACB: Biblioteconomia em Santa Catarina, Florianópolis, v. 22, n. 2, ESPECIAL, p. 161-179, abr./ jul., 2017. Anais do $35^{\circ}$ Painel Biblioteconomia Santa Catarina.

Chapecó

tange às questões técnicas e gerenciais, os bibliotecários com atuação nas unidades escolares integrantes da SDR/GERED, estimula o trabalho cooperativo, bem como representa estes profissionais perante o Órgão Central.

\subsection{Encontro Regional de Educação em Ciência da Informação - Região Sul}

A Associação Brasileira de Educação em Ciência da Informação (ABECIN), desde sua criação em 1967, tem buscado reunir os docentes dos cursos de Biblioteconomia e Ciência da Informação, no âmbito da graduação, em torno de uma questão central: a qualidade de ensino. Nos dias 14 e 15 de julho de 2016, foi realizado na Universidade do Estado de Santa Catarina (UDESC) o Encontro dos Docentes da Região Sul, para propor um espaço para reflexão e debate sobre a demanda, perfil e formação nos cursos de Biblioteconomia, Arquivologia, Museologia, Ciência da Informação e Gestão da Informação no sul do país. Neste evento, a Vice-Presidente do CRB-14 (11 a Gestão) participou da Mesa de Discussão: "Lei 12.244: Discussão sobre iniciativas, capacitação e proposta para criação do sistema nacional de bibliotecas escolares". Na oportunidade, foi abordada a trajetória, a luta e as ações dos órgãos de classe para criação do cargo de Bibliotecário no Plano de Cargos e Salários do Magistério Público e o projeto para implantação de uma Rede de Bibliotecas nas escolas públicas estaduais.

\subsection{Reapresentação do Projeto de Lei para criação do Cargo de Bibliotecário nas Escolas}

Em agosto de 2016, a Deputada Estadual Luciane Carminatti protocolou na Assembleia Legislativa do Estado o projeto para criação do cargo de Bibliotecário para atuar nas escolas. Para a Deputada, "a Lei Federal determina a criação de uma biblioteca em cada escola do país até 2020, mas o cargo não é regulamentado na rede estadual catarinense. Professores catarinenses são deslocados da função e retirados da sala de aula". Destaca ainda, que a demanda partiu de profissionais, estudantes e entidades de classe da Biblioteconomia, além de gestores, diretores e professores que são deslocados do cargo. O Projeto de Lei Complementar 013.1 acrescentará o cargo de Bibliotecário à chamada Lei dos ACTs (Admitido em Caráter Temporário), aprovada em Santa Catarina em 2015, e é uma exigência antiga do setor.

\subsection{Termo de Cooperação Técnica com o Ministério Público de Santa Catarina}

Em dezembro de 2016, foi assinado o Termo de Cooperação Técnica com o Ministério Público do Estado de Santa Catarina (MPSC). Esse tem por objetivo a realização de ações integradas entre o MPSC e o CRB-14, em toda a sua área de atuação (estado de Santa Catarina). A parceria busca analisar as condições de funcionamento de unidades escolares situadas nos municípios catarinenses, por meio de Revista ACB: Biblioteconomia em Santa Catarina, Florianópolis (Brasil) - ISSN 1414-0594 
Revista ACB: Biblioteconomia em Santa Catarina, Florianópolis, v. 22, n. 2, ESPECIAL, p. 161-179, abr./ jul., 2017. Anais do $35^{\circ}$ Painel Biblioteconomia Santa Catarina.

Chapecó

visitas semanais ou mensais pelos membros do MPSC, dos conselheiros e bibliotecários fiscais do CRB14 em todo o Estado de Santa Catarina. A parceria também possibilita a troca de informações, resultados e diagnósticos sobre irregularidades nas áreas de educação e áreas afins, notadamente quanto as Bibliotecas convenentes nas esferas de suas atribuições e finalidades nas unidades visitadas.

\subsection{Diagnóstico das Bibliotecas Escolares}

Em resultado do Termo de Cooperação Técnica com o MPSC, está em execução o Diagnóstico da Situação das Bibliotecas Escolares do Estado de Santa Catarina. Para coleta dos dados está sendo utilizado um formulário desenvolvido com base no documento "Biblioteca escolar como espaço de produção do conhecimento: Parâmetros para bibliotecas escolares", desenvolvido pelo Grupo de Estudos em Biblioteca Escolar da Escola de Ciência GEBE/UFMG, sob a coordenação de Campello (2010), regulamentado pela Resolução CFB n. 119/2011. Para a elaboração do formulário foi utilizado, ainda, o "Questionário Técnico" utilizado pelos Bibliotecários Fiscais, que foi criado pelo CRB-8, aprovado pelo CFB, para utilização no processo fiscalizatório. O diagnóstico pretende apresentar a situação das Bibliotecas Escolares Catarinenses no que tange as informações sobre os recursos materiais e humanos, acervo e serviços considerando os aspectos inerentes a Lei $n^{\circ}$ 12.244/2010 e estudos já realizados sobre Bibliotecas Escolares no Brasil.

\subsection{Programa de Apoio às Atividades de Fiscalização dos Conselhos Regionais de Biblioteconomia - (PAFIS)}

O PAFIS tem como objetivo auxiliar financeiramente o trabalho de fiscalização dos Conselhos Regionais de Biblioteconomia do Brasil. O projeto do CRB-14 foi apresentado para melhorar a atividade fiscalizatória no Estado. A meta é realizar 100 visitas de rotina em instituições localizadas na cidade de Florianópolis e 100 visitas de rotina em instituições localizadas na cidade de Joinville e seus arredores. São contemplados no cronograma os municípios de Araquari, Corupá, Florianópolis, Garuva, Guaramirim, Jaraguá do Sul, Joinville, Pomerode, São Bento do Sul, São Francisco do Sul e Schroeder, com data prevista para término em dezembro 2017. Com a retomada do processo fiscalizatório mais ativo no Estado de Santa Catarina, almeja-se ampliar a oportunidade de emprego para o bibliotecário, assim como ampliar o número de inscritos ativos no CRB-14 e, ainda, reduzir o número de inadimplentes. Deseja-se, também, a valorização e reconhecimento profissional através das informações disseminadas durante as visitas de rotina.

Revista ACB: Biblioteconomia em Santa Catarina, Florianópolis (Brasil) - ISSN 1414-0594 
Revista ACB: Biblioteconomia em Santa Catarina, Florianópolis, v. 22, n. 2, ESPECIAL, p. 161-179, abr./ jul., 2017. Anais do $35^{\circ}$ Painel Biblioteconomia Santa Catarina.

Chapecó

\section{CONSIDERAÇÕES FINAIS}

Conclui-se, com a identificação dos avanços, das perspectivas e das limitações da Lei $\mathrm{n}^{\circ}$ 12.244/2010, que a criação da referida Lei é um grande avanço para o setor, porém sua eficácia ainda deve ser comprovada, e medidas devem ser tomadas, principalmente no setor público, para a concretização da implementação da Lei em questão. Considera-se, ainda, que esta pesquisa poderá subsidiar as futuras interlocuções e contribuir na condução de um debate mais efetivo nas diferentes esferas políticas do Estado. Destaca-se a importância da inserção de todos os bibliotecários e de todos os acadêmicos dos cursos de Biblioteconomia do Estado, na luta pela valorização da Biblioteca Escolar, visando o cumprimento e efetiva aplicação da Lei $n^{\circ} 12.244 / 2010$, de forma a impedir que ela seja esquecida.

\section{REFERÊNCIAS}

ARAÚJO, F. P. A biblioteca escolar na pauta do Congresso Nacional. Biblioteca Escolar em Revista, Ribeirão Preto; v. 4, n. 1, p. 26-36. 2015. Disponível em:

<http://www.revistas.usp.br/berev/article/view/106614/105208>. Acesso em: 20 fev. 2017.

BICHERI, A. L. A.; ALMEIDA JUNIOR, O. F. Bibliotecário escolar: um mediador de leitura. Biblioteca Escolar em Revista, Ribeirão Preto; v. 2, n. 1, p. 41-54. 2013. Disponível em:

<http://www.revistas.usp.br/berev/article/view/106585/105180>. Acesso em: 24 fev. 2017.

BRAGA, A. A.; PAULA, R. S. L. A biblioteca escolar e sua representação educativa. Cadernos de Educação, Tecnologia e Sociedade, Inhumas, v. 5, p. 245-257, 2014. Disponível em: <http://cadernosets.inhumas.ifg.edu.br/index.php/cadernosets/article/viewFile/190/97>. Acesso em: 08 mar. 2017.

BRASIL. Lei $\mathrm{n}^{\circ}$ 12.244, de 24 de maio de 2010. Dispõe sobre a universalização das bibliotecas nas instituições de ensino do País. Diário Oficial [da] República Federativa do Brasil, Poder Executivo, Brasília, 25 mai. 2010. Seção 1, p. 3.

CAMPELLO, B. S. Bibliotecas escolares e Biblioteconomia escolar no Brasil. Biblioteca Escolar em Revista, Ribeirão Preto; v. 4, n. 1, p. 1-25. 2015. Disponível em: <http://www.revistas.usp.br/berev/article/view/106613/105207>. Acesso em: 20 fev. 2017.

CAMPELLO, B. S. (Coord.). Biblioteca escolar como espaço de produção do conhecimento: Parâmetros para bibliotecas escolares, Belo Horizonte: UFMG, 2010. Disponível em: <http://gebe.eci.ufmg.br/images/stories/padroesparabibliotecasescolares.pdf>. Acesso em 09 mar. 2017.

CAMPELLO, B. S. et al. Parâmetros para bibliotecas escolares brasileiras: fundamentos de sua elaboração. Informação \& Sociedade: Estudos, João Pessoa; v. 21, n. 2, p. 105-120. maio/ago. 2011. Revista ACB: Biblioteconomia em Santa Catarina, Florianópolis (Brasil) - ISSN 1414-0594 
Revista ACB: Biblioteconomia em Santa Catarina, Florianópolis, v. 22, n. 2, ESPECIAL, p. 161-179, abr./ jul., 2017. Anais do $35^{\circ}$ Painel Biblioteconomia Santa Catarina.

Chapecó

Disponível em: <http://www.ies.ufpb.br/ojs/index.php/ies/article/view/10451/5965>. Acesso em: 24 fev. 2017.

A universalização de bibliotecas nas escolas: reflexos da lei 12.244. PontodeAcesso, Salvador; v. 10, n. 2, p. 39-58. 2016. Disponível em:

<https://portalseer.ufba.br/index.php/revistaici/article/view/13609/11653>. Acesso em: 01 mar. 2017.

CASTRO FILHO, C. M.; COPPOLA JUNIOR, C. Biblioteca escolar e a lei 12.244/2010: caminhos para implantação. Biblioteca Escolar em Revista, Ribeirão Preto; v. 1, n. 1, p. 30-41. 2012.

Disponível em: <http://www.revistas.usp.br/berev/article/view/106556>. Acesso em: 21 fev. 2017.

CHAGAS, F. A. O. A Invisibilidade das Bibliotecas Escolares. In: Congresso Ibero-Americano em Investigação Qualitativa, 5., 2016, Porto. Atas... Porto: CIAIQ, 2016. v. 1, p. 672-680. Disponível em: <http://proceedings.ciaiq.org/index.php/ciaiq2016/article/view/656/645>. Acesso em: 24 fev. 2017.

. Bibliotecas escolares: um espaço contraditório. Revista Pesquisa Qualitativa, São Paulo, v. 4, n. 6, p. 390-407, dez. 2016. Disponível em:

<http://rpq.revista.sepq.org.br/index.php/rpq/article/view/60/48>. Acesso em: 08 mar. 2017.

COPPOLA JUNIOR, C.; CASTRO FILHO, C. M. Bibliotecas escolares no ensino fundamental: caminhos para a implantação. Biblionline, João Pessoa, v. 8, n. 2, p. 3-15, 2012. Disponível em: <http://periodicos.ufpb.br/ojs2/index.php/biblio/article/view/12284/8633>. Acesso em: 08 mar 2017.

DA SILVA, J. F. M.; SIQUEIRA, I. Biblioteca escolar como uma questão de direitos humanos.

Biblioteca Escolar em Revista, Ribeirão Preto, v. 3, n. 1, p. 38-50, 2014. Disponível em: <http://www.revistas.usp.br/berev/article/view/106603/105197>. Acesso em: 08 mar. 2017.

FERRAREZI L.; SOUSA, L. M. A. Nos meandros das políticas públicas: a biblioteca escolar em (dis)curso. Biblioteca Escolar em Revista, Ribeirão Preto; v. 3, n. 1, p. 73-88. 2014. Disponível em: <http://www.revistas.usp.br/berev/article/view/106605/105199>. Acesso em: 20 fev. 2017.

FRAGOSO, G. M. A lei e seus desdobramentos. Biblioteca Escolar: que espaço é esse? Rio de Janeiro, ano XXI, boletim 14, p. 12-17, out. 2011. Disponível em: <http://amormino.com.br/livros/20150213biblioteca-escolar-que-e.pdf>. Acesso em: 08 mar. 2017. (Sério Salto para o Futuro).

FUNDAÇÃO DE AMPARO À PESQUISA DO ESTADO DE SÃO PAULO. SciELO: A Scientific Electronic Library Online. Disponível em: <http://www.scielo.br/?lng=pt >. Acesso em 08 mar. 2017.

GARCEZ, E. F. et. al. Um projeto de rede de bibliotecas para as escolas públicas estaduais de Santa Catarina, Brasil: relato de experiência(s). Perspectivas em Ciência da Informação, Belo Horizonte, v. 21, n. 2, p. 237-262, abr./jun. 2016. Disponível em:

<http://portaldeperiodicos.eci.ufmg.br/index.php/pci/article/view/2468/1764>. Acesso em: 08 mar. 2017.

GOOGLE Acadêmico. Disponível em: <https://scholar.google.com.br/>. Acesso em: 08 mar. 2017.

LEITE, S. M.; PINHEIRO M. I. S.; CARDOSO A. C.; FREITAS M. T. Lei 12.244/10: uma esperança para as bibliotecas brasileiras. In: Congresso Brasileiro de Biblioteconomia, Documentação e Ciência da

Revista ACB: Biblioteconomia em Santa Catarina, Florianópolis (Brasil) - ISSN 1414-0594

Esta obra está licenciada sob uma Licença Creative Commons. 
Revista ACB: Biblioteconomia em Santa Catarina, Florianópolis, v. 22, n. 2, ESPECIAL, p. 161-179, abr./ jul., 2017. Anais do $35^{\circ}$ Painel Biblioteconomia Santa Catarina.

Chapecó

Informação, 25., 2013, Florianópolis. Anais... Florianópolis: FEBAB, 2013. p. 367-376. Disponível em: <https://portal.febab.org.br/anais/article/view/1253/1254> Acesso em: 20 fev. 2017.

MOLLO, G.; NÓBREGA, M. J. Introdução. Biblioteca Escolar: que espaço é esse? Rio de Janeiro, ano XXI, boletim 14, p. 4-11, out. 2011. Disponível em: <http://amormino.com.br/livros/20150213biblioteca-escolar-que-e.pdf>. Acesso em: 08 mar. 2017. (Sério Salto para o Futuro).

MORENO E. A. Diagnóstico das bibliotecas escolares do município de Jaraguá do Sul (SC) segundo a lei 12.244/2010. Revista ACB: Biblioteconomia em Santa Catarina, Florianópolis; v. 19, n. 1, p. 23-32. 2014. Disponível em: <https://revista.acbsc.org.br/racb/article/view/946/pdf_84> Acesso em: 20 fev. 2017.

SEVERINO, A. J. Metodologia do trabalho científico. 23. ed. São Paulo: Cortez, 2007.

SILVA, J. L. C. Perspectivas históricas da biblioteca escolar no Brasil: análise da Lei 12.244/10 que dispõe sobre a universalização das bibliotecas escolares. Revista ACB: Biblioteconomia em Santa Catarina, Florianópolis; v. 16, n. 2, p. 489-517. 2011. Disponível em:

<https://revista.acbsc.org.br/racb/article/view/797/pdf_63>. Acesso em: 20 fev. 2017.

UNIVERSIDADE FEDERAL DE MINAS GERAIS. Escola de Ciência da Informação. Grupo de Estudos em Biblioteca Escolar. LIBES: Literatura Brasileira em Biblioteca Escolar. Disponível em: <http://libes.eci.ufmg.br/>. Acesso em 08 mar. 2017.

UNIVERSIDADE FEDERAL DO PARANÁ. BRAPCI: Base Referencial de Revistas de Biblioteconomia e Ciência da Informação. Disponível em: 〈http://www.brapci.ufpr.br/brapci/index.php〉. Acesso em 08 mar. 2017.

VAHLDICK, V. et al. Diagnóstico para melhoria contínua nas bibliotecas escolares do município de Indaial/SC. Biblioteca Escolar em Revista, Ribeirão Preto; v. 5, n. 2, p. 44-60, 2017. Disponível em: <http://www.revistas.usp.br/berev/article/view/112937>. Acesso em 05 mai. 2017

\title{
LAW 12.244/2010 DEVELOPMENT, PERSPECTIVE AND LIMITATIONS FROM ITS APPLICABILITY: BRAZILIAN LITERATURE REVIES AND ACTIONS TAKEN BY THE CLASS ENTITY AT SANTA CATARINA STATE (BRAZIL)
}

\begin{abstract}
This article presents the textual analysis results from articles published at on-line journals since the new Law 12.244/2010, which contemplates the libraries universalization at the educational institutions in Brazil. It presents a short review about School Library role, mission and duties, and also about the Librarian responsibilities. The articles search was done consulting the following on-line Data Bases: LIBES, BRAPCI, ScIELO and Scholar Google. We sought to identify the Law applicability, meaning to verify its development, perspectives and limitations, which can contribute to follow a more effective debate between the academic community, teachers, librarians and the local public managers. It describes the actions taken by the class entity and by the associative movement from Librarianship in Santa Catarina, meaning to enforce the Law $12.244 / 2010$.
\end{abstract}

Keywords: School libraries. School librarian. Law 12.244/2010. CRB-14. 
Juliano Ricardo Zimmermann - Graduado em Biblioteconomia - habilitação em gestão da informação pela Universidade do Estado de Santa Catarina (UDESC). Graduado em Administração Pública pela Universidade do Estado de Santa Catarina (UDESC). Foi Bibliotecário na UNIVILLE e na Fundação Catarinense de Educação Especial (FCEE). Foi gerente na Secretaria de Planejamento e Gestão da Prefeitura Municipal de Biguaçu. Atuou como Assessor Parlamentar. Desenvolve trabalhos na área de Administração Pública, assessorando entidades de cunho sócio-comunitário. Presidiu os conselhos municipais de Habitação de Interesse Social e o dos Direitos da Criança e do Adolescente - CMDCA, neste último coordenou a eleição dos Conselheiros Tutelares do município entre 2007 e 2008. Bibliotecário efetivo da Secretaria de Estado de Turismo, Cultura e Esporte de Santa Catarina. Presidente do Conselho Regional de Biblioteconomia - Gestão 2015/2017, Professor Efetivo na Escola Técnica Geração, nos cursos técnicos de Administração e Segurança do Trabalho. E-mail: julianopublico@gmail.com

Viviane Carolina de Paula - Graduada em Biblioteconomia, habilitação em Gestão da Informação pela UDESC. Bibliotecária Fiscal do Conselho Regional de Biblioteconomia 14ạ Região. E-mail: vivianecarol2003@hotmail.com

Maria Lourdes Blatt Ohira - Mestrado em Biblioteconomia na área de concentração de Planejamento e Administração de Sistemas de Informação pela Pontifícia Universidade Católica de Campinas - PUCCAMP (1998). Especialização em Gestão de Arquivos Públicos e Empresariais pela Universidade Federal de Santa Catarina - UFSC (2004). Graduação em Biblioteconomia pela Universidade do Estado de Santa Catarina - UDESC (1976). Foi professora titular do Curso de Biblioteconomia - Habilitação em Gestão da Informação do Departamento de Biblioteconomia e Gestão da Informação da Universidade do Estado de Santa Catarina - UDESC. Professora Aposentada do Departamento de Biblioteconomia da UDESC. VicePresidente do Conselho Regional de Biblioteconomia 14a Região, 11a Gestão. E-mail: blattohira@gmail.com 